\section{Do vets and doctors face similar ethical challenges?}

\begin{abstract}
What does a vet do when a pet owner wants them to carry out heroic surgery on a dying animal? Rebecca Coombes asks whether doctors and vets can learn from each other's ethical dilemmas
\end{abstract}

\begin{abstract}
The ethical problems facing doctors and vets obviously differ in some ways. A veterinary surgeon, for example, can decide when a treatment is no longer valuable and opt for euthanasia. This course is not open to doctors. And a doctor has to seek the consent of a patient for treatment whereas veterinary surgeons need to steer a course between their own professional opinion and the wishes of pet owners. The animal itself has no rights. Moreover, there is no NHS for animals, and decisions about euthanasia often have to be made in the light of an owner's ability to pay for a lengthy course of life extending treatment. But, when considering these ethical issues with members of both the veterinary and medical profession, some interesting parallels emerge.
\end{abstract}

At a recent discussion at the BMA, organised by the BMJ, Lord Soulsby, chairman of the British Veterinary Association's ethics committee, and Michael Wilks, chairman of the BMA's ethics committee, considered their fundamentally different approaches to various ethical dilemmas. They also discovered a surprising amount of common ground.

A shared issue was that of consent. Humans can give consent to invasive treatment near the end of their lives, but what about a sick old pet whose owner wants it kept alive even though it might be better off dead? Are there parallels with a doctor who is faced with an incapacitated patient?

Fifty years ago, when vets didn't have the drugs and didn't do major surgery, euthanasia was a straightforward decision, says Lord Soulsby. By contrast, today's vets can perform "heroic" acts of intervention. But just because they can, doesn't mean they should, he said.

"These days one can use chemotherapy and radiotherapy of a very severe nature, but one's Could child cruelty, such as that suffered by Victoria Climbié (above), be reduced if vets were obliged to report cases of pet cruelty to the police, because of life that animal is going to enjoy. euthanasia," he said. mal alive?"

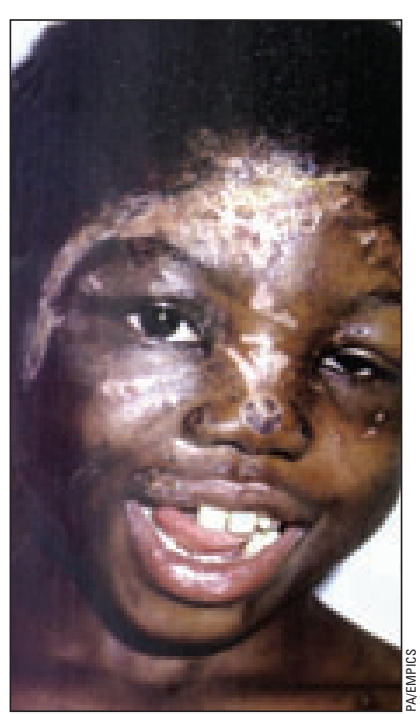

tain amount of power in the therapeutic relationship according to how much information is given and the way it is nuanced.

"In addition, a lot of doctors will deal with people who don't have full capacity-mental illness, people who are unconscious They rely on the opinion of others, a family member, to help the doctors decide. Similarly, a veterinarian is going to be taking the owner of the animal's opinion as a fairly significant factor in the decision."

In fact, Dr Wilks thought a pet owner had more power over a treatment decision than a patient's relative. "Relatives have no rights. Parents have responsibility but we have seen in many court cases, recently [that of] Charlotte Wyatt, where doctors disagree with parents about the best interest of the child, then the matter goes to court for adjudication."

If a pet owner has more power than a relative of an incapacitated patient over a treatment decision, can they therefore require a veterinary surgeon to destroy a healthy animal?

Lord Soulsby says that it's an the connections between the two?

got to consider whether it is worth it in terms of the quality of The majority of [vets] faced with major intervention might in fact say, despite what you the owner feel, I would recommend

Today, younger vets were increasingly regarding euthanasia as a failure of their competence, Lord Soulsby added. "They would rather see the animal alive. That just adds to the dilemma-how far do you want to push it to keep an ani-

Dr Wilks said that it would be wrong to imagine that doctors didn't face similar dilemmas. "It might be said that consent is the big difference between a healthcare professional looking after an animal and one looking after a human being. But I think that is only true up to a point. We say we deal with fully informed consent with our human patients. I think a doctor does retain a cerescapable fact. "You do cases where there is nothing wrong with the animal-it is just a nuisance-and the owner wants to get rid of it. And that is a big dilemma. The vast majority of vets do comply with owners request to destroy the anima but with great reluctance and attempt to talk to them out of it, to have it taken to a shelter organisation."

Are there any parallels between euthanasia in animals and the discussions about euthanasia in humans? Dr Wilks said, "We would only discuss voluntary euthanasia-the ending of a life of a patient at their persistent competent request." By contrast, the euthanasia of an animal was an entirely involuntary process. But Dr Wilks wanted to know if vets could detect any elements of "voluntariness" in the process-do some animals want to die? didn't think it possible to tell. "Up the scale to higher primates there may be something. But with dogs and cats I don't think so. However, you will find owners who will swear that the animal communicated with them and wanted to die." doctor, he was very familiar with making best interest judgments for a patient in a complete vacuum. "I work a lot in police stations. If I'm dealing with someone who is completely out of it on cocaine and alcohol and cannot communicate with me and I have absolutely no idea what their basic wishes are I assume that they will wish to be treated in terms of basic medical care. To that extent, my work is similar to yours.'

There were shared issues of patient confidentiality. Like doctors, veterinary surgeons have a duty of confidentiality to their clients, but it is not absolute.

Lord Soulsby said that in gross cases of abuse he would inform the police. Dr Wilks agreed: "None of these issues of confidentiality have complete privilege," and that's as it should be, he added.

Lord Soulsby suggested that vets also had an ethical responsibility to humans. "Abuse in the family often starts with abusing the pet. There are certain injuries you may see, and if a vet is up to scratch he will say there is something wrong here. There has been a lot of debate of what then a vet should do-should they inform the police?"

Dr Wilks, a forensic physician

Lord Soulsby said that he

Dr Wilks said that, as a 